\title{
Efficacy of Low dose Magnesium Sulphate in Indian Eclamptic Women
}

\author{
Dr.R.Sasikala $\mathrm{MD}(\mathrm{OG})^{1,}$ Dr.A.Devi Lakshmi $\mathrm{MD}(\mathrm{OG})^{2}$ \\ ${ }^{1}$ Assistant Professor, Dept of OBS \& GYN, Coimbatore medical college,, Coimbatore \\ ${ }^{2}$ Assistant Professor, Dept of OBS \&GYN, Coimbatore medical college, Coimbatore
}

\section{Aim And Objectives}

The safety and efficacy of low dose Magnesium Sulphate regime in the management of convulsion in Antepartum / Intrapartum /Postpartum eclampsia patients. This study also compares the maternal outcome in patients treated with Pritchard and Dhaka regimen.

\section{Materials And Methods}

This study was conducted at Govt.coimbatore Medical college in the Department of Obstetrics \& Gynaecology during the period of June 2015 to June 2016 and 100 eclampsia patients including antepartum eclampsia, intrapartum eclampsia, post partum eclampsia were included for the purpose of this study.Magnesium Sulphate was used for the management of eclampsia. 50 eclamptic patients were treated with Pritchard regimen and other 50 with Dhaka regimen.

\section{Inclusion Criteria}

All eclamptic women antepartum, intrapartum, postpartum patients were included in the study irrespective of their age, gestational age, parity and status of booking.

\section{Exclusion Criteria}

Patients who have already received Magnesium sulphate outside.

Patients with known epilepsy

Patients with known Heart Block, Renal Failure

Onset of seizures more than $72 \mathrm{hrs}$ after delivery in post partum eclampsia cases

Totally about 134 eclampsia cases were admitted between June 2015 to 2016. Of which 34 patients were excluded according to exclusion criteria

\section{Study Design}

Randomized control Trial

Group P: Treatment of 50 patients randomly with Pritchard's regime.

Group D: Treatment of 50 patients randomly with Dhaka regimen of Magnesium Sulphate.

\section{Outcome Measures:}

Recurrence of fits was considered as the primary outcome measure. outcome of mother as maternal morbidity and mortality were compared. .

\section{Results And Analysis}

Table-1

\begin{tabular}{|l|l|l|l|l|}
\hline \multicolumn{1}{|c|}{ BMI } & Dhaka regime & \multicolumn{2}{l|}{ Pritchard regime } \\
& \multicolumn{2}{|l|}{} \\
\cline { 2 - 5 } & $(\mathbf{n = 5 0 )}$ & $\mathbf{1 0 0 \%})$ & $\mathbf{( n = 5 0 )}$ & $\mathbf{1 0 0 \% )}$ \\
\hline Low ( <19.8) & $\mathbf{5}$ & $\mathbf{1 0 . 0} \%$ & 0 & $0 \%$ \\
\hline Normal (19.8 to 26) & $\mathbf{4 1}$ & $82.0 \%$ & $\mathbf{4 5}$ & $\mathbf{9 0 \%}$ \\
\hline High (26 to 29) & $\mathbf{3}$ & $6 \%$ & $\mathbf{4}$ & $8.0 \%$ \\
\hline Obese ( $>29)$ & $\mathbf{1}$ & $\mathbf{2 \%}$ & $\mathbf{1}$ & $\mathbf{2 . 0 \%}$ \\
\hline Total 50 & $\mathbf{5 0}$ & $\mathbf{1 0 0 \%}$ & $\mathbf{5 0}$ & $\mathbf{1 0 0 . 0 \%}$ \\
\hline
\end{tabular}




\section{Distribution of Body Mass Index}

In Dhaka regimen group, 41 patients were with normal BMI.5patients were with low BMI. In Pritchard regimen group 1 obese, 4 withhigh BMI and 45 with normal BMI were treated. The

$\mathrm{p}$ value is 0.03

Table : 2 types Of Eclampsia

\begin{tabular}{|l|l|l|l|l|}
\hline \multirow{2}{*}{$\begin{array}{l}\text { TYPES OF } \\
\text { ECLAMPSIA }\end{array}$} & \multicolumn{2}{|l|}{ Dhaka regime } & \multicolumn{2}{l|}{ Pritchard regime } \\
\cline { 2 - 5 } & $(\mathbf{n = 5 0 )}$ & $\mathbf{( 1 0 0 \% )}$ & $\mathbf{( n = 5 0 )}$ & $\mathbf{( 1 0 0 \% )}$ \\
\hline Antepartum & 40 & $80.0 \%$ & 43 & $86.0 \%$ \\
\hline Intrapartum & 4 & $8.0 \%$ & 1 & $2.0 \%$ \\
\hline Postpartum & 6 & $12.0 \%$ & 6 & $12.0 \%$ \\
\hline Total & 50 & $100.00 \%$ & 50 & $100.00 \%$ \\
\hline
\end{tabular}

Among the 83 antepartum eclampsia patients, 40 were treated underDhaka regimen. 43 patients were treated under Pritchard regimen. 6postpartum eclampsia patients were treated under Dhaka regimen as well as under Pritchard regimen. 1 intrapartum eclampsia patient was treated with Pritchard

Table: 3 Recurrence Of Fits

\begin{tabular}{|l|l|l|l|l|l|}
\hline & \multirow{2}{*}{$\begin{array}{l}\text { Sits } \\
\text { No }\end{array}$} & & \multicolumn{2}{|l|}{ Dhaka regimen } & $\begin{array}{l}\text { Pritchard } \\
\text { regimen }\end{array}$ \\
\cline { 3 - 6 } & & $(\mathbf{n = 5 0 )}$ & $\mathbf{( 1 0 0 \% )}$ & $\mathbf{( n = 5 0 )}$ & $(\mathbf{1 0 0 \% )}$ \\
\hline 1 & Nil & 49 & $98 \%$ & 49 & $98 \%$ \\
\hline 2 & $\begin{array}{l}\text { Recurrence } \\
\text { of fits }\end{array}$ & 1 & $2 \%$ & 1.0 & $2 \%$ \\
\hline
\end{tabular}

One patient from each regime had recurrence of fits. The patient in the Dhaka regime developed another convulsion after 3 hours of loading dose. One patient who developed recurrence of fit in Pritchard regime had that convulsion 2 hours after loading dose

Table : 4 Maternal Complications

\begin{tabular}{|l|l|l|l|l|}
\hline \multirow{2}{*}{} & \multicolumn{2}{|c|}{ Dhaka regime } & \multicolumn{2}{c|}{ Pritchard regime } \\
\cline { 2 - 5 } & $(\mathbf{n = 5 0 )}$ & $\mathbf{( 1 0 0 \% )}$ & $\mathbf{( n = 5 0 ) (}$ & $\mathbf{1 0 0 \%})$ \\
\hline Abruption & 2 & $4.0 \%$ & 2 & $4.0 \%$ \\
\hline HELLP & 1 & $2.0 \%$ & 1 & $2.0 \%$ \\
\hline Pulmonary Edema & 5 & $10.0 \%$ & 2 & $4.0 \%$ \\
\hline Cerebro vascular accident & 1 & $2.0 \%$ & - & $0 \%$ \\
\hline Nil & 41 & $82.0 \%$ & 45 & $90.0 \%$ \\
\hline Total & 50 & $100.00 \%$ & 50 & $100.00 \%$ \\
\hline
\end{tabular}

In Dhaka regimen 2 patients had abruption,1 had HELLP and 5 had pulmonary edema.One patient developed occipital lobe infarct. In Pritchard regime 2 had abruption. 1 patient had HELLP and 2 had pulmonary edema

Table : 5

\begin{tabular}{|l|l|l|l|l|}
\hline \multirow{2}{*}{ MATERNAL OUTCOME } & \multicolumn{2}{|c|}{ Dhaka regime } & \multicolumn{2}{c|}{ Pritchard regime } \\
\cline { 2 - 5 } & $\mathbf{( n = 5 0 )}$ & $\mathbf{( 1 0 0 \% )}$ & $\mathbf{( n = 5 0 )}$ & $\mathbf{( 1 0 0 \% )}$ \\
\hline Alive & 49 & $98.0 \%$ & 49 & $98.0 \%$ \\
\hline Death & 1 & $2.0 \%$ & 1 & $2.0 \%$ \\
\hline Total & 50 & $100.00 \%$ & 50 & $100.00 \%$ \\
\hline
\end{tabular}

In this study, out of the 100 patients, 98 were discharged from the hospital without any sequlae. 2 patients died due to complication of eclampsia.

\section{Discussion}

The Maternal Morbidity is very much decreased with the control of eclamptic fits. MgSO4 is an anticonvulsant drug used in the treatment of Antepartuum, intrapartum, postpartum eclampsia which has a wider margin of safety and rapid onset of action. Although rare the toxicity symptoms of magnesium toxicity can be 
corrected by antidote calcium gluconate which is readily available. Magnesium sulphate act as an ideal anti convulsant drug in the control of eclamptic fits.

\section{Recurrence of Eclampsia}

In this study, the recurrence of eclamptic fits was $2 \%$.Reccurence ofconvulsions occurred both in Dhaka regime (one patient) and Pritchard regime (one patient). Collaborative Eclampsia Trial Group (1995)extensively studied 1687 women with eclampsia, They compared the efficacy of MgSO4 with other anti convulsants namely Diazepam and phenytoin level . . They showed 9.7\% recurrence of seizures in the $\mathrm{MgSO} 4$ regime.

Begum et al (1998) studied 65 eclamptic patients with Low dose MgSO4 ( Dhaka regime ). $1.5 \%$ of patients had recurrent convulsions Bissallah A Ekele et al (2009) studied 121 patients with eclampsia and treated with Ultra short regime ( Sokotto regime). In ultra short regime loading dose of $4 \mathrm{~g}$ of $20 \% \mathrm{MgSO} 4$ intravenously followed by $10 \mathrm{gm}$ of $50 \% \mathrm{MgSO} 4$ intramuscularly given. No maintenance dose was given for those patients. $7.4 \%$ of patients developed recurrence seizures.

\section{Maternal Mortality}

In this present study, 2 patients $(2 \%)$ died due to complication of eclampsia. One patient in Dhaka regime died of intra cranial haemorrhage. One patient in Pritchard regime died of pulmonary edema..In Collaborative Eclampsia Trial ,the maternal mortality was 3.8\% when treated with Magnesium sulphate. Bissallah A Ekele et al (2009) reported 12 maternal deaths in 121 patients (9.9\%).Shika sheth et al (2010)49 studied 66 eclampsia patients and they categorized them into three groups. The patients were treated with Standard Pritchard regime, single loading dose regime and low dose MgSO4 regime respectively. Maternal mortality was $7.6 \%$ in Pritchard regime and 5\% in single loading dose. There was no maternal mortality in patients treated with low dose regime.

\section{Maternal Morbidity}

In this present study, the complication of eclampsia observed in patients treatedpulmonary edema $(10 \%)$ and cerebro vascular accidents $(2 \%)$. In patients treated under Pritchard regime the incidence of abruption and HELLP were similar as in Dhaka regime . $4 \%$ of patients under Pritchard had pulmonary edema. The maternal morbidity between Dhaka regime and Pritchard regime was statistically significant. $(p<0.05)$ 91Shika seth et al (2010) reported pulmonary edema in patients treated with Pritchard regime( $3.8 \%)$ and with single loading dose (5\%). Cortical blindness (5\%) reported in patients treated with low dose MgSO4. This cortical blindness complication also observed in our present study in a patient treated under Dhaka regime

\section{Conclusion}

Most of the Indian women considered to be of low to normal BMI need only low dose magnesium sulphate which is sufficient for them Efficacy of low dose $\mathrm{MgSO} 4$ regime in controlling the convulsions, and its effect on maternal outcome is equivalent to standard Pritchard regime. Low dose magnesium sulphate is equally good enough to control eclampsia, thereby preventing magnesium toxicity though it is rare Poor manpower and waste of time in monitoring the $\mathrm{Mg}$ toxicity symptoms can be avoided in low dose MgSO4. 